\title{
Establishment of Role-Player as a Virtual Identity in Twitter Social Media
}

\author{
R P Nugraha \\ Universitas Mercu Buana, Jakarta \\ rahmadya.putra@gmail.com
}

\begin{abstract}
This study focused on the activity of virtual identity on one of Twitter's social media platforms, namely Role play. Role-playing is a role play where individuals do on social media to act, play, socialize by becoming or playing someone else's role. The individual who carries out that role is called Roleplayer. The role is carried out in the form of characters from idolized figures such as Idol Artists, Cartoon Characters, Super Heroes, and also self-built fictional characters. The aim of this Role-playing is to create a virtual identity by following the original characters of the idol to communicate with each other so as to create a social space in cyberspace. This study is supported by the theory of Social Construction in which the theory explains the relationship between identity and construction that is built in communication, especially on social media. The perspective in this study is constructivist and uses qualitative research types in order to explain this study in a broader way. This research is using phenomenology method. Role-play virtual identity formed through 4 processes, namely the thought process that includes knowledge about the character, the desire to portray the character, then the process of making a Role play account on Twitter social media, and the results of actions that contain the process of self-formation, experience, and reality social.
\end{abstract}

Keywords: Social Media, Virtual Identity, Role-player

\section{INTRODUCTION}

Identity is something that is inherent and becomes the main foundation for every individual in this world. Identity is formed and attached to individuals with various processes that take time and influence all sides of life. Every individual must have an identity, and each identity must refer to one particular individual. In current era, the advancement of the media is very rapid and cannot be stopped. No exception for new media in which there are social media and the internet as the forum. Unwittingly, social media becomes a necessity in communicating for people in this era. The way to create a social media account is also an easy thing and it does not require a long time to get it.

New media is the media that offers digitization, convergence, interactivity and the development of network in relation to the making and sending of messages. The ability to provide interactivity makes new media users capable to have information choices to be consumed as well as control information outputs and carry out the intended choices. The ability to offer an interactivity is the central concept of understanding the new media [1].

It is undeniable that currently we are in the context of digitization, where individuals are connected through the internet and create a new world: the virtual world [2]. Similar woth 
the real life, each individual has an identity that he wants to display and it influences how he interacts with other individuals in the virtual world. Virtual identity is a differentiator for each individual in virtual life. In various contexts, this virtual identity becomes a person's alter ego in his real life. It is not surprising if then what appears in cyberspace becomes a person's pseudo identity.[3]

"A virtual identity is a persona that is implied when communicating online" [4]. Von Kokswijk added that virtual identity or online identity is a person's appearance in cyberspace (online), where he is free to determine what he wants to be in the virtual world, so that the level of truth of that identity is very small and easy to change according to individual desires. People can be smarter, sexier, rougher and even crazier in the virtual world.

Explains the expression "The medium is the message" as determinative and controlling in the sense of medium's operational and practical fact. At this point, it is stated that the medium will be personal, social consequences and new technology will become the extension of each person. At this point, the power of medium or medium content for controlling and directing the people has reduced with the social network sites. Because people are no longer consuming the content of the medium passively, but they have become an active producer, that is the reason of decreasing[5]. The use of media by people is explained in two ways: on the basis of content (content gratifications) and on the basis of the experience of using media (process gratifications). When social media use is compared with traditional media use, it can be expressed that it gives more content satisfaction by creating more chance for communicating to the people. In addition, in terms of usage and satisfaction theory, social media's main motivations can be regarded as allowing the person to learn social events related to daily life, staying in touch with his / her loved ones, getting away from daily life responsibilities and sharing a photo. [6]

The presence of social media is something new in the community. One of the most popular social media is the Twitter community. Social media is not only used to exchange information between users, but as a portal to create a virtual network of friends and a medium for sharing data. Based on the results described on (http://wearesocial.sg survey in January 2016) [7], Twitter ranked seventh with the most active users in Indonesia. Twitter social media is also used by South Korean artists to communicate with their fans. In the existence of a Twitter account belonging to South Korean artists and containing the interaction of idols and fans, there is an imitation phenomenon by fans. Imitation is done by imitating the username, made to resemble the username of the South Korean artist. The identity displayed and the tweets posted are like a favorite artist. Fans call this phenomenon in the term of Role-play. Role-play can be said as a role-playing activity.

Roleplay is a fan activity where someone pretends to be a character that they idolizedin sum, they play a role. In fandom world, celebrity roleplaying not only can be done in theatrical stage act (live performance), but also be done in the world of cyber, that is through social networking website's account. In this research, the media that is chosen as the sample is Twitter because in Twitter the interaction is more rapid and intense while the blog is the supporting element to the Twitter account that cannot be left behind since it contains information that corresponds to what is happening in the Twitter account of the role-players. Twitter also picked as the chosen platform because Twitter's original style of posting is limited only for 140 character per tweet(posts in Twitter), it makes posts in Twitter more like short narratives or conversations - compared to other roleplaying platform such as Facebook and Tumblr which enable the role-player to post much longer postings (sometimes even long note about their 'life'), in Twitter the role-players' posts more like direct conversation with their 'fans', which 
agrees with roleplaying's original attempt: to form a fan service from the previously unreachable celebrities.[8]

Role-play is defined as an act played by an Individual (Role-player) in a Twitter social media space, who plays the role of his Idol figure as well as writes tweets and posts everything as if he is the Idol. Role-play is also defined as a "game" that positions oneself to resemble the person he idolizes. Writing Tweets as if they are an idol they admire with their creativity as a player. They interact between Role-players and create groups and qualify them.

In the world of Role-player we will be able to find a number of things that previously could only be done in real life. Role-player can make a family, have a partner and even adopt children. These things should only be done if they are in the real world and go through a time consuming process. Thus, it is said that the Role-play world has adopted real life so that Roleplayers often cannot distinguish which is the real world and which is the virtual world or what they often call "Fake World".

\section{RESEARCH METHOD}

The author used the Constructivism paradigm Constructivism is often applied to fields such as psychology and education to describe how we understand things and how we see the world. As stated by Jesse Delia, professor and developer of constructivism as it relates to interpersonal communication, "The core idea is that people have experiences through which they come to understand their worlds; and, out of that experience, they develop constructs, or, repetitive ways of giving meaning to their world" [9]

Phenomenology is the study of a phenomenon perceived by human beings at a deeper level of understanding in a specific situation with Vol. 5 No. 1 (June 2018) Phenomenology 218 a detailed description and interpretation of lived experiences through bracketing [11]; as takenfor-granted assumptions by the researchers. Perhaps, the use of bracketing strategy according to Husserl, is essential for the research to gain insights into lived experiences. Speziale and Carpenter (2007) add that bracketing is an effective way to ensure validity of data collection and analysis in phenomenological research.

In addition, this research used qualitative study that a form of social action that stresses on the way of people interpret, and make sense of their experiences to understand the social reality of individuals [12]. It makes the use of interviews, diaries, journals, classroom observations and immersions; and open-ended questionnaires to obtain, 3nalyse, and interpret the data content analysis of visual and textual materials, and oral history [13]. It is exploratory, and seeks to explain 'how' and 'why' a particular social phenomenon, or program, operates as it does in a particular context. It tries to help us to understand the social world in which we live, and why things are the way they are [14].

The study subjects were considered as study targets or as one aspect to be studied and observed. In general, the author chose the people in the Role-player community on Twitter as the study subjects. The inclusion criteria to select informants for this study were as follows: Have a Role-player account on Twitter, Has been actively playing Role-player for at least 1 year, and Play Role-player on Twitter with an intensity of at least 3 hours a day.

\section{RESULTS AND DISCUSSION}

Being a Role-player means carrying a certain character in mind beforehand. Roleplayer is free to choose what character he plays. There are no age, gender, or nationality 
limitations for a character played by a Role-player. That means Role-player is free to determine who the character he wants to play for himself.

A woman may portray a male character and become a man in the life of Role-play. The opposite is also the case which a man may portray a female character in the life of Role-play. Consideration about the character selection to be played also varied, the consideration of character selection could be described as follows: (1) Acting as an idol. Character selection could be based on interest about the artist or idol that would be played. The reason that was often said by a Role-player about the consideration of choosing a character was that he liked and idolized the character. This statement was supported by statement from one interviewee interviewed by the author:

Well in the early days, I used to portray the one ... such as ... the bias.... the artist to whom I liked, that's first reason.

The initial foundation for someone to play the role of another person in Role play was that the person admired the character. Bias is a word used for someone who idolizes the artist or idol. Bias can be said as another word for idolization.

For me... I do like to characterize him because he is a bias too, I like that character

In this case someone played the character because he liked the character and played it, it meant that there was an interpersonal attraction, where interpersonal attraction refers to one's feelings with others. These feelings include like and dislike feelings towards the person. There was a cognitive process that occurred in a Role-player that provided knowledge about the character of the idol, and thinking on how to become and play that role. (2) Looking for characters similar to the original character of himself.

Every human being has different and unique traits and characters. Often a Role-player felt not suitable for a character and the nature of the character he played even though the character was his idol at the same time. There were uncomfortable feelings even to the point of not being able to portray, and this eventually led the Role-player to change the character they were playing and looked for other people whose trait and character were almost the same as him.

So .. what is it called, I felt like ... his trait and character were different with my character, I'm really different with him, so I finally get it now, that I want to change that character, I ... um ... I don't want to use if we don't have the same age and similar nature....so that we are not too different...

I portrayed her because she was a bias too, I liked that character. After that I looked for another one who was not that old, because I when I played an old RP it was like there was a distance with the young RP. Because now there are many younger people, right? They who were born in '98 and '99 years, that's it. And also because she is beautiful, then sometimes the idol is really good.

The question that arose when such an argument like this emerged was how they as fans or Role-player could know the nature of the idol. When they tried to portray the idol to be a character in Role-play, it was a basic demand for them to find out the biodata, photos, hobbies, likes, and habits of the idol. Not infrequently it provided general knowledge about how people's views about the character of the idol, so that the Role-players could learn and adjust their trait and nature. 


\subsection{Basic reasons to act a Role-play}

As the author said before, Role play has been established since 2011 and it firstly established on Facebook with a fairly long history. The existence of Role play is proven until now, where Role play still has so many players. Various reasons support this, starting from the absence of activities that ultimately make Role-player to fill spare time by playing Role-play. Then, there is a desire to make new friends and acquaintances from various regions.

Yes, in junior high school. Formerly it was the Facebook era, I already had a Korean account like that, then I asked whether this was an official account or what, oh he said it was a role-player account. In 2011 I really wanted to play, finally in early 2012, early or middle, I played it, played it on Twitter ... then I don't know why, well ... just when I played, what's the name, I met new people, then we became friends, everything seemed like wow there were many people who wanted to be friends despite your physics, it's about loving you without eh without seeing your original nature, they only knew your nature from your type,

The desire to have friends without considering themselves physically was one of the reasons why Role-player still existed to find friends or best friends. Formerly a distant friend or someone known as a distant acquaintance that has never been met can also be found through "Pen Pals". Same with Pen pals who have never been met, so are generally friendships in Roleplay. They can make good friends only by knowing the figure of the person through the life of Role-play.

It seems that....it's just as exciting as my friend said, we can meet a new friend, and then we're pretending to be an idol and can also update about the idol on Twitter too, like there is a fan base too.

Through this role play, everyone in it does not care about the real physicality of someone who is behind the character. When in real life someone who plays Role-play does not feel confident about himself, he can feel the comfort of an acceptance from his friends in the role play.

\subsection{Communication in Role play}

Communications are shorter and more frequent than when letters were the norm and response time has greatly diminished. Instant messaging has created another method of interaction, one where the length of messages is shorter and the style of the interaction is more conversational. Broadcast technologies like Twitter transform these short bursts of communication from one-on-one conversations to little news (or trivia) programs : which we can tune in" whenever we want an update or have something to say. Online communication tools also have the potential to increase our awareness of the movements of our professional or social contacts. Twitter, for instance, offers us an update of things people we know happen to be doing at a particular point of time. This phenomenon has been referred as social proprioception by Clive Thompson [15] named after the physical quality of proprioception that tells a creature where its extremities are by the reception of stimuli produced within the organism. Social proprioception tells us where the nodes of our community are and provides a sense of connectedness to and awareness of others without direct communication. Internet is the third place where people connect with friends, build a sense of togetherness. 
This role play uses Twitter social media as its communication tool. Time makes communication more widespread and also makes communication to be unlimited. In the past a person could communicate with people through face to face, talk directly, then it developed into communication via telephone, email, then to communication through social media which at this time becomes a habit and a human need.

The most basic feature of social networking sites is to ensure interpersonal communication, or in other words, to allow face-to-face communication in a virtual environment. The use of these networks for the purpose of maintaining or dating old friendships by a person, reveals the socialization features of social networking sites (Eke et al.2014).[16] Besides, social network sites have the social networking characteristics because they enable to establish new friendships, to meet people who have common interests, even access to people that they can not reach in the daily life. Another feature of social network sites is being a social navigation. The meaning of Social navigation feature is a person can connect with his/her friends and thanks to them he/she can reach the resources, information or people that he/she needed.[17]

The characters played in this role play are so diverse. We can play a cartoon character, anime, super hero, etc. without any restrictions. In this study, the author found the uniqueness that occurred in Role play, namely the existence of Role-player who did not play an idol in general but played the character that the author mentioned above.

Basically anime, super hero or cartoon Role-player has the same concept as ordinary Role-player who plays the human character. The difference is only the activities carried out. If he acts as a super hero, the activities carried out in Imagine or daily life are acting and acting like a super hero that is fighting and combating the enemies.

For example, well, there is a sign like this ("), I pull out the sword bla bla bla. I cut him with the X pattern, something like that.

In this study, the author did not succeed in interviewing the anime Role-player from Twitter. But the author got an informant who came from Facebook. So the author made a difference that could be learned from between using Role play on Twitter or Facebook.

The initial establishment of Facebook Role play was almost the same as Twitter roleplay, the difference is that Facebook can be considered as the beginning of the establishment of Role-play. The way to play Role play on Facebook is quite diverse, can use your own account or can enter into a group that houses personal accounts that want to turn into Role play accounts.

Another thing that distinguishes is how to communicate through Imagine. In Facebook Role-play, they don't know exactly what Imagine is. They just call it an activity in quotes (")

No, it's like ... oh how can I explain? Well, the point is, if the quotes are like that, we want to do something like that. Like for example I want to take a wallet or want to do something then I use quotes.

The formation of a Role-player virtual identity continues over time, although he changes character after character, the learning process and the experience continue to exist and increase knowledge about himself.

In the figure above, it is stated that there are 4 processes that occur which include thinking processes, action processes, outcome and further processes. Like what has been explained before, the above processes will always take place continually since the formation of virtual identity is done through the learning, adjustment, and continuous experience processes. 
In addition to the impacts described above, there were also negative impacts in the form of a crime that was detrimental to themselves and others, but this was also counterbalanced by the positive impacts emerge from the role play, namely: (1) Train us to be able to write; Imagine and Plotting can encourage us to be able to write a story line or situation better, this can help us learn new grammar and vocabulary. (2) Got new friends; For some people, finding a new friend is a difficult thing and cannot be done haphazardly. However, in the life of Role play we can make good friends without caring about the physical, material, authentic life of each other.

\section{CONCLUSIONS}

Becoming a Rollover is a form of self-existence performed through social media, in which there is a communication process built through an artificial, virtual identity. Selfrepresentation and virtual identities used by roleplay actors tend to indicate an anonymity of the role-players. Role-players use a virtual identity adopted from the idol without considering the real identity of gender, age, ethnicity, ethnicity, class and others. Anonymity of this virtual identity gives role-players the freedom to experiment with their identities that are very different from real life. Internet and role play encourage fans to experiment by forming selfrepresentations and virtual identities with anonymous accounts, expressing themselves without exception, building relationship and interacting

The process of the formation of Role-player virtual identity is performed from the main process, namely the thinking process that includes knowledge about the character being played and also the desire to portray the character, then proceed by the action process marked by creating a twitter account. Then the outcome is the formation of an account, which is followed by a continued process in which there is a process of self-adjustment, self and identity negotiation, there is an experience taken and there is also a learning process so that the activities of identity formation take place continuously.

\section{REFERENCES}

[1] R. Briandana and N. A. Dwityas, "Media Literacy: An Analysis of Social Media Usage among Millennials," Int. J. English Lit. Soc. Sci., 2019.

[2] K. Sabbagh, R. Friedrich, B. El-Darwiche, M. Singh, and S. Ganediwalla, "Maximizing the Impact of Digitization," Glob. Inf. Technol. Rep. 2012, 2012.

[3] S. Stephen, Race and ethnicity: Culture, identity and representation, Second edition. 2014.

[4] J. Van Kokswijk, "Granting Personality to a Virtual Identity,” Soc. Sci., 2008.

[5] P. Rose, “ Understanding New Media: Extending Marshall McLuhan, Robert K. Logan (2016)," Explor. Media Ecol., 2019.

[6] A. Quan-Haase and A. L. Young, "Uses and Gratifications of Social Media: A Comparison of Facebook and Instant Messaging," Bull. Sci. Technol. Soc., 2010.

[7] S. Kemp and We Are Social, "Digital in 2016," Www. Wearesocial.Com, 2016. [Online]. Available: http://wearesocial.com/sg/special-reports/digital2016\%5Cnhttp://www.slideshare.net/wearesocialsg/digital-in-2016. [Accessed: 10Nov-2019].

[8] G. Turner, Understanding celebrity. 2004.

[9] E. Griffin, A. Ledbetter, and G. Sparks, A First Look at Communication Theory (9th ed.). 2015. 
[10] B. R. Burleson, “A constructivist approach to listening,” Int. J. List., 2011.

[11] R. E. Gearing, "Bracketing in research: A typology," Qualitative Health Research. 2004.

[12] H. J. S. Speziale, H. J. S. Streubert, and D. R. Carpenter, "Ethnography in Practice, Education, and Administration," in Qualitative Research in Nursing: Advancing the Humanistic Imperative, 2011.

[13] M. Zohrabi, "Theory and Practice in Language Studies," Theory Pract. Lang. Stud., 2013.

[14] D. E. Polkinghorne, "Language and meaning: Data collection in qualitative research," Journal of Counseling Psychology. 2005.

[15] D. C. Brouwer and R. Asen, "Introduction: Public modalities, or the metaphors we theorize by," Public Modalities: Rhetoric, Culture, Media, and The Shape of Public Life. 2010.

[16] H. N. Eke, C. O. Omekwu, and J. N. Odoh, "The use of social networking sites among the undergraduate students of university of Nigeria, Nsukka," Libr. Philos. Pract., 2014.

[17] M. Thelwall, "Chapter 2 Social Network Sites. Users and Uses," Advances in Computers. 2009. 